\title{
A Study of Micro-Dimpled Groove Texture in Friction Reduction
}

\section{Yuan Wei ( $\nabla$ iamywei@nwpu.edu.cn )}

Northwestern Polytechnical University https://orcid.org/0000-0003-4577-4619

\section{Xu Liu}

Xidian University School of Mechano-Electronic Engineering

\section{Simon S. Park}

University of Calgary

\section{Robert Tomkowski}

KTH Royal Institute of Technology: Kungliga Tekniska Hogskolan

\section{Andreas Archenti}

KTH Royal Institute of Technology: Kungliga Tekniska Hogskolan

\section{Research Article}

Keywords: Surface texturing, Laser, Friction minimization, Computational fluid dynamics

Posted Date: March 12th, 2021

DOI: https://doi.org/10.21203/rs.3.rs-319410/v1

License: (c) (1) This work is licensed under a Creative Commons Attribution 4.0 International License. Read Full License 


\title{
A Study of Micro-Dimpled Groove Texture in Friction Reduction
}

Yuan Wei ${ }^{1,4, \#}, \mathrm{Xu} \mathrm{Liu}^{2}$, Simon S. Park $^{3}$, Robert Tomkowski ${ }^{3}$ and Andreas Archenti ${ }^{3}$

1 Frontiers Science Center for Flexible Electronics, Xi'an Institute of Flexible Electronics (IFE) and Xi'an Institute of Biomedical Materials \& Engineering, Northwestern Polytechnical University, Xi'an 710072, China.

2 School of Mechano-Electronic Engineering, Xidian University, Xi'an, 710071, China

3 Department of Mechanical and Manufacturing Engineering, University of Calgary, Calgary, AB T2N 1N4, Canada

4 Manufacturing and Metrology Systems, KTH Royal Institute of Technology, Stockholm 10044, Sweden

\# Corresponding Author / E-mail: iamywei@nwpu.edu.cn, TEL: +86-8849-2151

\section{KEYWORDS:}

Surface texturing, Laser, Friction minimization, Computational fluid dynamics

\begin{abstract}
:
Friction control is a vital green technology for reaching sustainable development goals, and surface texturing is effective and efficient at reducing friction. In this study, a novel preparation scheme involving dimpled groove texture is proposed. A pulsed laser marking system is used to make the dimpled grooves. Due to the unique design and process to make the proposed texture, texturing time can be greatly minimized compared to the conventional micro-groove texture technology. A computational fluid dynamics (CFD) model that considers the dimple surface angle is employed to aid the design of the texture and to predict the performance of the texture under certain conditions. Reciprocating sliding tests are preformed to evaluate the effects of the texture on friction reduction. Textures with different densities are used in the experiments. The results suggest that the dimpled groove reduces the coefficient of friction by $6 \%$ with less density distribution on the sample surface; nevertheless, denser densities may reverse the result. The simulation results suggest that the texture may perform better under pressure of
\end{abstract}




\section{Introduction}

Energy and material loss due to tribological contacts significantly affects energy consumption globally. Around $23 \%$ of the world's total energy consumption is used to overcome friction and to remanufacture contacting parts because of material loss (Holmberg and Erdemir 2017). Thus, minimizing friction in mechanical systems are vital for saving energy and reducing waste in our society.

Surface texture for reducing friction has become a focus of worldwide research. For decades, researches have demonstrated that certain micro-textures can minimize friction and wear. Several studies indicate that surface texture decreases the friction coefficient under dry and lubricated conditions (Chang, Guo et al. 2019, Zhong, Zheng et al. 2019) and improves the lubrication condition of friction pairs by enhancing the hydrodynamic pressure effect (Rosenkranz, Costa et al. 2019, Wei, Tomkowski et al. 2020). Surface texture techniques have been widely applied in several areas, such as cutting tools (Wei, Kim et al. 2017, Kang, Fu et al. 2018, Li, Qiu et al. 2020), bearings (Lu, Gao et al. 2020, Tomar and Sharma 2020), cylinders (Zhang, Chen et al. 2018, Rao, Sheng et al. 2019), pistons (Chen, Zhang et al. 2019, Venkateswara babu, Syed et al. 2020), rotating shafts, etc.

Surface textures are usually formed by fabricating appropriate micro-geometry, such as arrays of micro dimples and micro grooves, on the working surface of the friction pair. It has strict requirements for the "appropriate micro-geometry" texture to significantly improve the lubrication and friction conditions between the friction pairs and minimize wear. Shape and geometrical parameters (Suh, Chae et al. 2010, $\mathrm{Su}$, Huang et al. 2019, Wang, Guo et al. 2019) play a critical role in determining a surface texture's tribological properties. Considerable research has been conducted on texture parameter optimization: texture effects greatly rely on shape (Schäfer, Reinert et al. 2018), size (Burlakova, Tyurin et al. 2019), depth (Panigrahi and Sarangi 2020), density (Dan, Xuefeng et al. 2020), area (Walker, Cinti et al. 2019), and orientation (Yagi, Matsunaka et al. 2021) of the texture. For a promising texture effect, it is important to maintain the precision of texture geometrical parameters. 
A variety of techniques have been employed to fabricate surface texturing, including machining processing, chemical etching, electrical discharge machining, energy beam etching and laser surface texture (LAT). Each method has its own characteristics in the texture features and texturing process. For instance, machining processing could generate micro dimples or micro grooves with accurate dimensions, but the texturing process needs high precision milling machine and time consuming. The electrical discharge machining process only works on the conductive workpiece and fabricate uniformed areal texture. In summary, most texturing approaches currently are high cost and low efficient, cannot fabricate the texture with a high precision. Those limitations draws back the texture application in the mechanical systems.

Compared to other texturing process, laser surface texture (LAT) (Mezzetta, Choi et al. 2018, Zhang, Guo et al. 2020) has notable potential to overcome the current limitations of texturing process. Laser surface texturing is a highly efficient, precise, versatile, and economical mothed to fabricate micro dimples and micro grooves. However, if the texturing process needs to remove a lot of material, as fabricating micro grooves or dense micro dimples, the over heating and larger heat affected zone (HAZ) must be considered.

In this study, we report on a novel dimpled groove texture fabricated using a commercial laser marking system. The effect of the dimpled groove texture is verified by experiments and simulations. We utilized the interval power output of pulsed laser to generate the dimpled groove texture. The material is removed by a certain moving speed laser beam. Compared to conventional micro groove fabricating, less removed material, less chance of overheated and minimized heat affected zone can be expected.

The dimpled groove texturing method is introduced in this study. To investigate the effect of dimpled groove texture on the tribological properties, lubricated reciprocating sliding tests are performed. Computational fluid dynamics (CFD) simulations are carried out as well to evaluate the texture effect numerically. Study results suggest that the commercial laser marking system is a low cost, effective, and efficient method for high-precision surface texture processing and that an appropriate dimpled groove texture minimizes friction. In addition, the density of the micro-dimpled texture is not invariably proportional to the amount that friction is reduced; in fact, the opposite effect emerges when the there is a high density of micro dimples. Consequently, texture density plays an important role in friction behaviour. 
This study's novel contributions are as follows: 1) a novel micro-dimpled groove texture, 2) the texturing method utilize the pulsed laser marking system, and 3) the finding that, contrary to existing research, a denser texture may increase friction.

\section{Texturing Method}

In this study, surface texture is produced using a commercial laser marking system. The schematic diagram of the system is shown in Fig. 3, and the specifications are listed in Table 1. A laser beam passes through a galvanometer scanner and field lens and then irradiates the workpiece surface directly. The scanner can quickly adjust the laser beam position using the two-axis mirror galvanometer system. The laser beam has a nearly Gaussian profile ( $>95 \%)$, shown as Fig. 2.

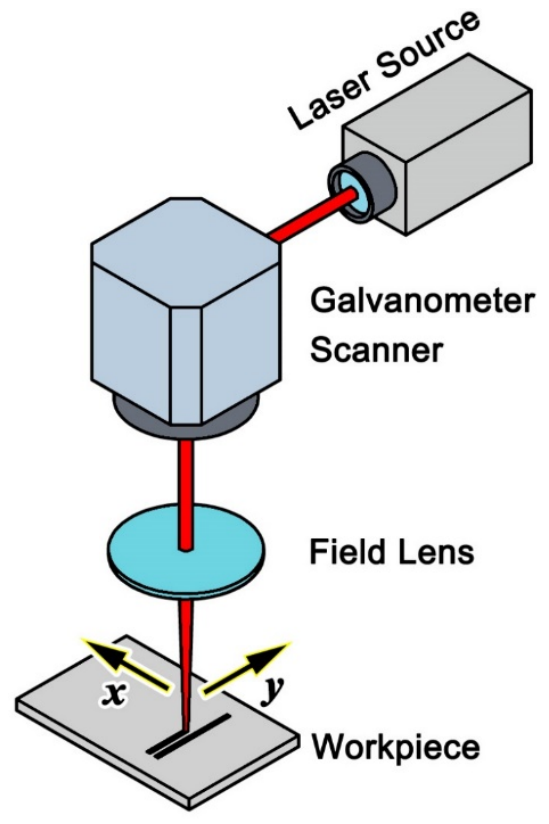

Fig. 1. Schematic diagram of the laser marking system

Table 1. Specifications of the laser marking system

\begin{tabular}{|c|c|}
\hline Output power & $\leq 20 \mathrm{~W}$ \\
\hline Wavelength & $1060 \mathrm{~nm}$ \\
\hline Pulse frequency & $20 \sim 200 \mathrm{kHz}$ \\
\hline Spot size & $50 \mu \mathrm{m}$ \\
\hline
\end{tabular}




\begin{tabular}{|c|c|}
\hline Spot moving speed & $\leq 7000 \mathrm{~mm} / \mathrm{s}$ \\
\hline
\end{tabular}

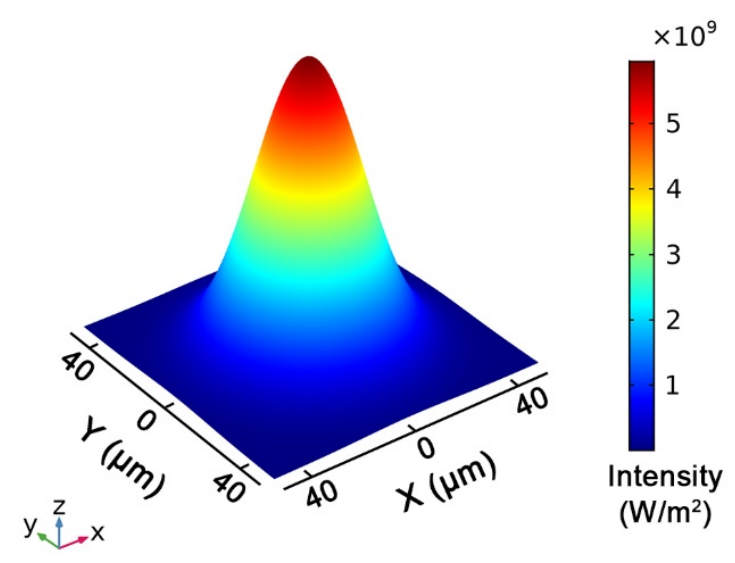

Fig. 2. The distribution (Gaussian) of laser beam profile.

AISI/ASTM 52100 bearing steel is selected as the workpiece material. The workpiece is machined as a cuboid with dimensions of $30 \mathrm{~mm} \times 15 \mathrm{~mm} \times 5 \mathrm{~mm}$. The contact surfaces, including the textured surface attached to the friction tester stage, are polished. The average surface roughness for the polished surfaces is $\mathrm{Sa}=0.2 \mu \mathrm{m}$ and $\mathrm{Sq}=0.3 \mu \mathrm{m}$. Textures are fabricated on the workpiece surfaces, the texture area is 450 $\mathrm{mm}^{2}$. During the texturing process, the laser output is set as $8 \mathrm{~W}$, the spot moving speed is $2000 \mathrm{~mm} / \mathrm{s}$ and the pulse frequency is $20 \mathrm{kHz}$. Fig. 3 shows the picture of the workpieces.

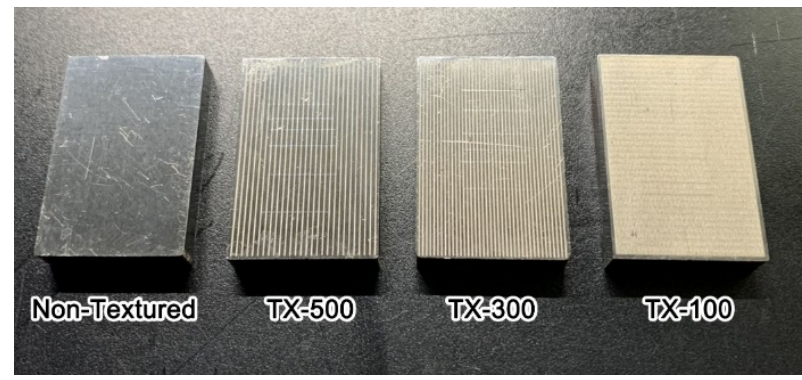

Fig. 3. The picture of the workpiece Non-textured, TX-500, TX-300 and TX-100.

The textured surfaces are observed using scanning electron microscopy (SEM), as shown in Fig. 4. The micro-groove, formed by tightly distributed micro-dimples, can be seen clearly, and this micro-groove is significantly different compared to the conventional laser-produced micro-grooves. Three different textures are prepared, each with a different distance between the dimpled grooves: $500 \mu \mathrm{m}$ (TX-500), $300 \mu \mathrm{m}$ (TX- 
300), and $100 \mu \mathrm{m}$ (TX-100). Consequently, the uniquely dimpled grooves demonstrate that the interval output of a pulsed laser creates novel formations during the surface texturing process.
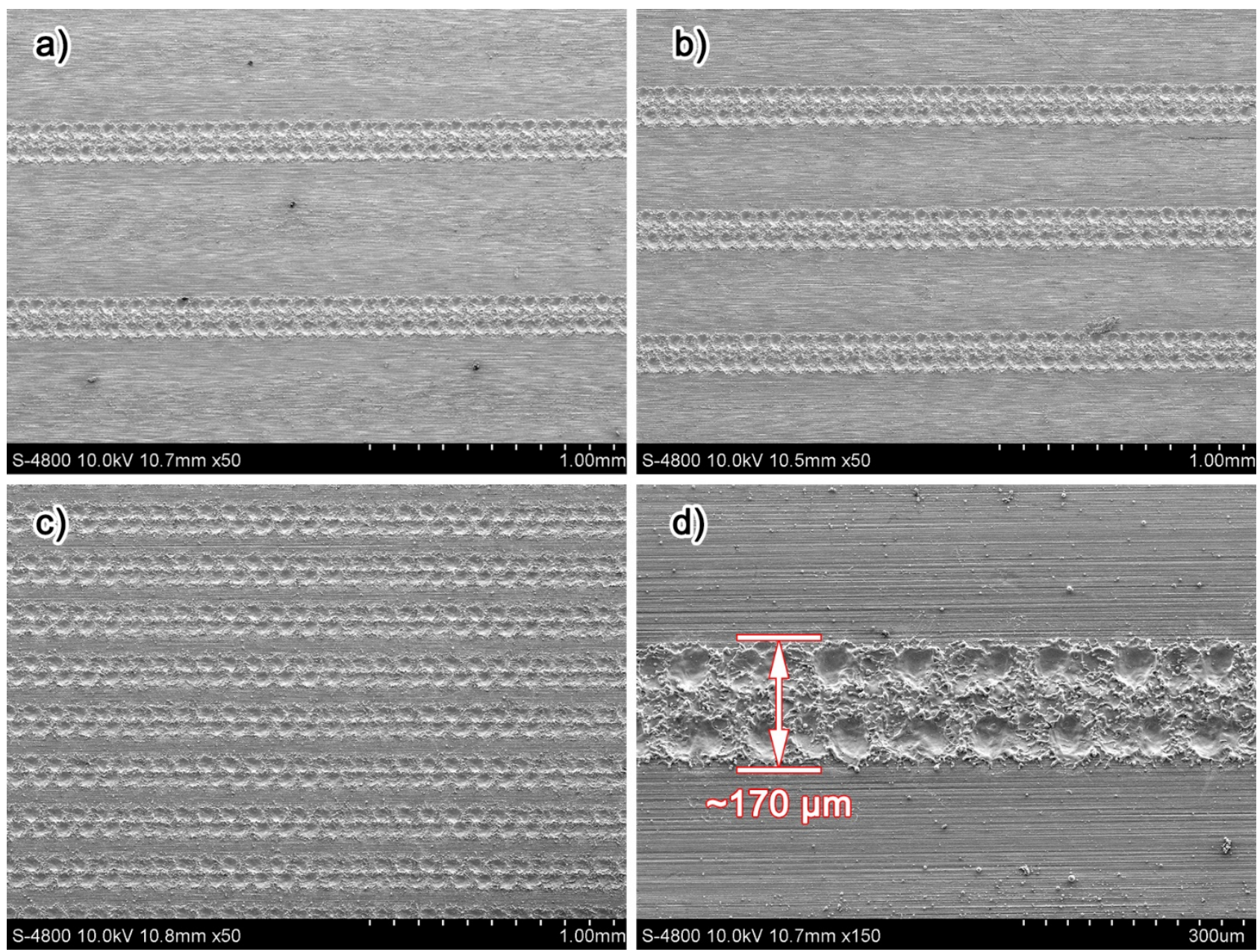

Fig. 4. SEM images of textured surfaces for a) TX-500, b) TX-300, c) TX-100 and d) a partially enlarged groove.

A partially enlarged view of a dimpled groove is shown in Fig. 4 d). The groove width is in the range of $180 \sim 200 \mu \mathrm{m}$, which is within the optimal range obtained in the simulation. The groove is formed by two rows of dimples, and each dimple has a diameter of approximately half of the groove width. The sputtering of the workpiece material can be seen at the outer edges of the dimples.

Characterization of the surface is achieved by a NanoMap1000 white light interferometer (WLI). Detailed surface profile could be obtained used WLI rather than SEM. Fig. 5. shows an image taken by WLI of a partially enlarged surface profile of a dimpled groove and the profile of a single dimple. The depth 
of the dimples is around $8 \mu \mathrm{m}$, which is within the optimal range (Wei, Tomkowski et al. 2020).

a)

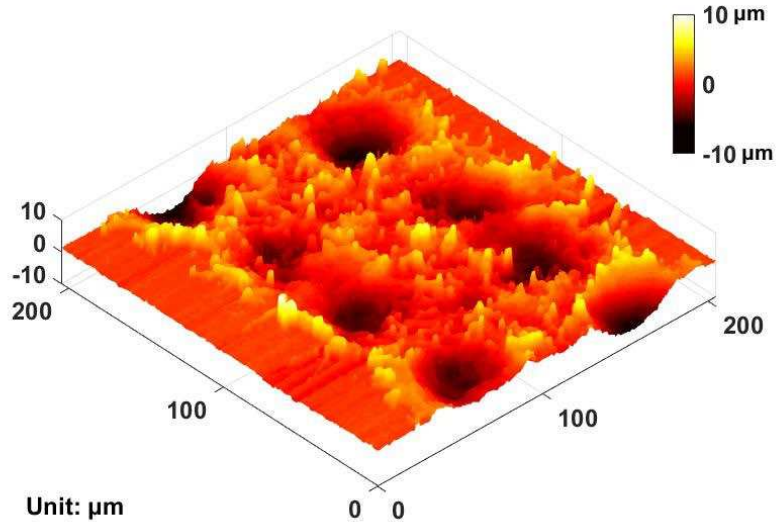

b)

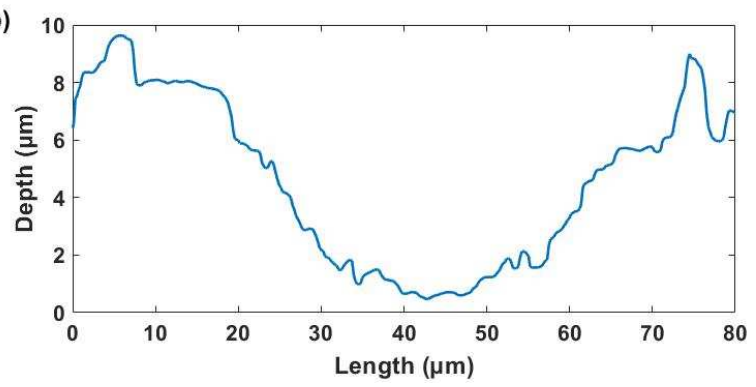

Fig. 5. a) Surface profile of the texture and b) profile of a single dimple section (obtained using a NanoMap1000 white light interferometer).

\section{Experiments}

The effect of the proposed laser surface texture in the tribological contacts have been evaluated through reciprocating sliding tests. The tests are performed using an MFT-R4000 reciprocating friction wear tester to verify the effect of texture on tribological contacts. The schematic diagram of the experiment setup is shown in Fig. 6. 


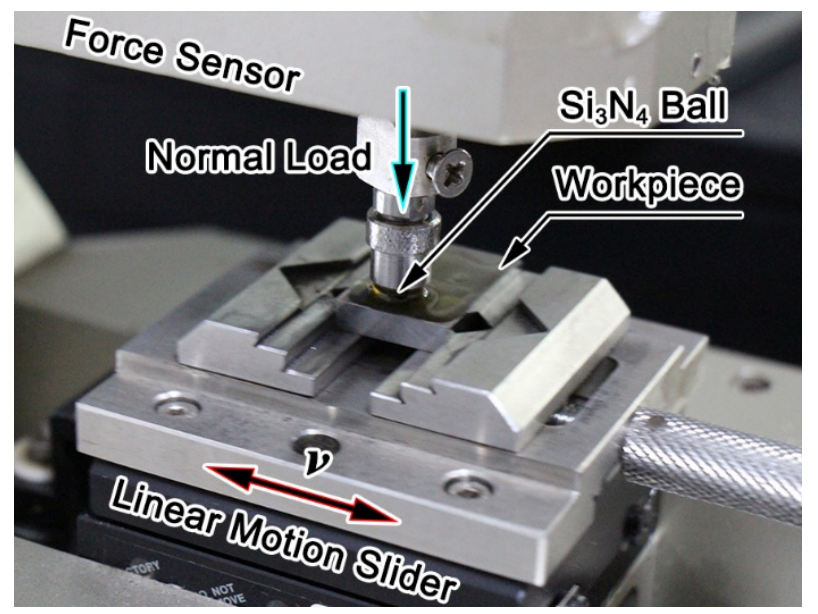

Fig. 6. Schematic diagram of the friction tester.

Silicon nitride $\left(\mathrm{Si}_{3} \mathrm{~N}_{4}\right)$ is selected as the other material for the friction pair. A $6 \mathrm{~mm}$-diameter silicon nitride ball is mounted on the tester, the properties of $\mathrm{Si}_{3} \mathrm{~N}_{4}$ are shown in Table 2. SAE 0W30 engine oil, a multiple-grade base oil blend, is selected as the lubricant, the properties of 0W30 engine oil are listed in Table 3. MFT-R4000 reciprocating friction wear tester allows the normal load being applied using standard weight. In total $1070 \mathrm{~g}$ standard weight, which is equal to $10.4 \mathrm{~N}$ approximately, is applied as normal load. The sliding speed is $0.01 \mathrm{~m} / \mathrm{s}$, and the sliding distance is $10 \mathrm{~mm}$. The tester is calibrated before performing the test, and the friction force is measured and recorded through the specific DAQ system and software, the sampling rate is $1000 \mathrm{~Hz}$. A non-textured surface sample is also prepared and tested as a reference.

The results of the reciprocating sliding tests are presented in Fig. 7, and as shown, the coefficient of friction (COF) is less when the distance between each groove is $500 \mu \mathrm{m}$ compared to the non-textured reference sample; consequently, friction is less with a textured surface. When the distance is reduced to 300 $\mu \mathrm{m}$ (TX-300), the COF changes only slightly; and when the distance drops to $100 \mu \mathrm{m}$, the COF increases, which means that as the distance becomes smaller between the grooves, the friction in the system is greater. 


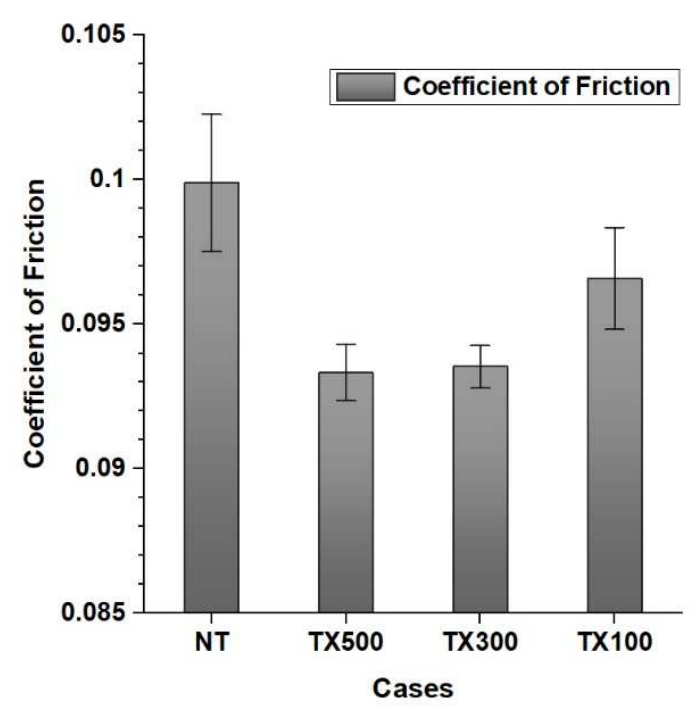

Fig. 7. Comparison of COFs in the non-textured case and textured cases.

The tests results suggest that, the proposed texture could reduce friction by $6 \%$ under lubricated condition. However, with the increase of the textured area, the coefficient of friction increase slightly.

\section{CFD Simulation and Discussion}

One vital mechanism for friction minimization under lubricated conditions is that the texture could generate additional hydrodynamic pressure to enhance the lubricant film. Thus, numerical modelling and simulation are used to investigate the effect of a texture on the lubricant film carrying capacity. The model provides a reference for understanding the results of the experiment, and a series of three-dimensional CFDbased simulations are performed.

The CFD model is designed base on the experimental design. A small flow area is picked up from the experimental setup, the length and width of the flow area is $5 \mathrm{~mm}$ and $4 \mathrm{~mm}$, as shown in Fig. 8 , the film thickness and the texture depth are both set at $10 \mu \mathrm{m}$. The model's texture distributed follows the experimental workpiece. The texture unit is designed based on the real dimple which is fabricated on the workpiece, the diameter is $70 \mu \mathrm{m}$ and the depth is $8 \mu \mathrm{m}$. The width of the dimpled groove is $170 \mu \mathrm{m}$. Fig. 8shows the model of TX-100 and boundary conditions, models of TX-500, TX-300 and Non-textured are also built respectively. For the boundary conditions, the inlets and outlets are defined as pressure-based; 
the operating pressure is set to $101,325 \mathrm{~Pa}$. The bottom wall and two side walls are stationary; the translational motion is set so that the top wall mimics the friction pair's relative motion, the translational motion is set as same as the $0.01 \mathrm{~m} / \mathrm{s}$.

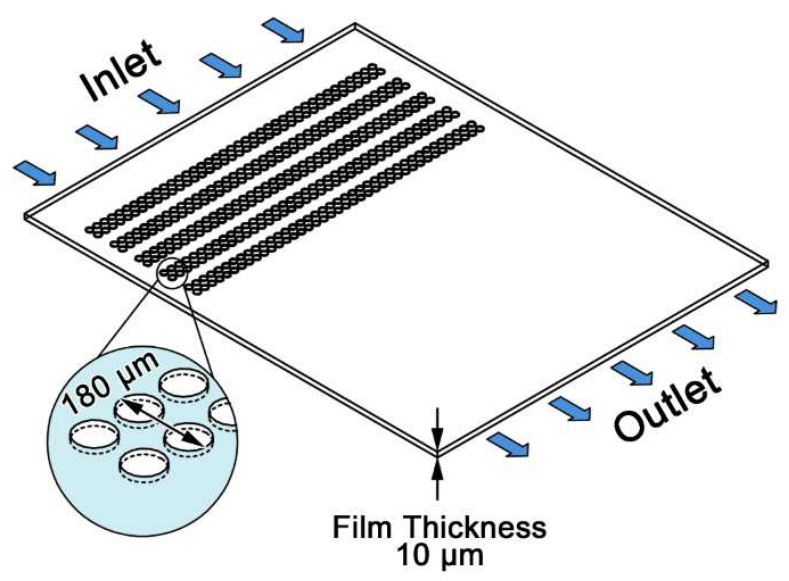

Fig. 8. Schematic of the computational fluid dynamics (CFD) model of TX-100 case.

CFD code ANSYS FLUENT is used in this study, the model is meshed with high-quality hexahedral mesh strategy. The total element number is in the range of the $3 \times 10^{5}$ to $4 \times 10^{5}$. The mass conservation equation (1) and momentum conservation equation (2), both of which need to be solved, are shown as follows:

\begin{tabular}{|c|c|}
\hline$\nabla \cdot v=0$ & (1) \\
\hline$\rho(v \cdot \nabla)=-\nabla p+\mu \cdot \nabla^{2} v$ & (2) \\
\hline
\end{tabular}

SAE 0W30 engine oil is the lubricant used in the simulation. The temperature-dependent properties of 0W30 engine oil are applied in the simulation. Two-phase flow is defined considering the cavitation, $0 \mathrm{~W} 30$ engine oil, and its vapour. The Zwart-Gerber-Belamri model defines the possible mass transfer between the two phases. The governing equation for mass transfer between two-phase in cavitation is the vapour transport equation shown as following:

$$
\frac{\partial}{\partial t}\left(\alpha_{v} \rho_{v}\right)+\nabla \cdot\left(\alpha_{v} \rho_{v} \mathbf{v}\right)=C_{e}-C_{c}
$$

where $C_{e}$ and $C_{c}$ account for the mass transfer between the two phases in cavitation. In ZwartGerber-Belamri model, which assume that all the bubbles in a system have same size, the mass transfer 
sources are defined as following:

If, $p \leq p_{v}$

$$
C_{e}=F_{\text {evap }} \cdot \frac{3 \cdot a_{n u e}\left(1-a_{v}\right) \cdot \rho_{v}}{R_{b}} \cdot \sqrt{\frac{2}{3} \cdot \frac{p-p_{v}}{\rho_{l}}}
$$

If, $p \geq p_{v}$

$$
C_{c}=F_{\text {cond }} \cdot \frac{3 \cdot a_{v} \cdot \rho_{v}}{R_{b}} \cdot \sqrt{\frac{2}{3} \cdot \frac{p-p_{v}}{\rho_{l}}}
$$

where evaporation coefficient $F_{\text {evap }}=50$, condensation coefficient $F_{\text {cond }}=0.01$, bubble radius $R_{b}$, nucleation site volume fraction $a_{n u e}=5.0 \times 10^{-4}, \rho_{l}$ is the lubricant density and $p_{v}$ is the saturated liquid pressure. The properties of the lubricant 0W30 oil and its vapour are listed in Table 3.

Table.3 Physical properties of 0W30 engine oil at room temperature.

\begin{tabular}{|c|l|}
\hline Density & $850 \mathrm{~kg} / \mathrm{m}^{3}$ \\
\hline Dynamic viscosity & $0.1422 \mathrm{~kg} / \mathrm{ms} @ 25^{\circ} \mathrm{C}$ \\
\hline Saturated pressure & $13 \mathrm{~Pa}$ \\
\hline Density of vapour & $2.5 \mathrm{~kg} / \mathrm{m}^{3}$ \\
\hline Dynamic viscosity of vapour & $2.5 \times 10^{-5} \mathrm{~kg} / \mathrm{ms} @ 25^{\circ} \mathrm{C}$ \\
\hline
\end{tabular}


(a)

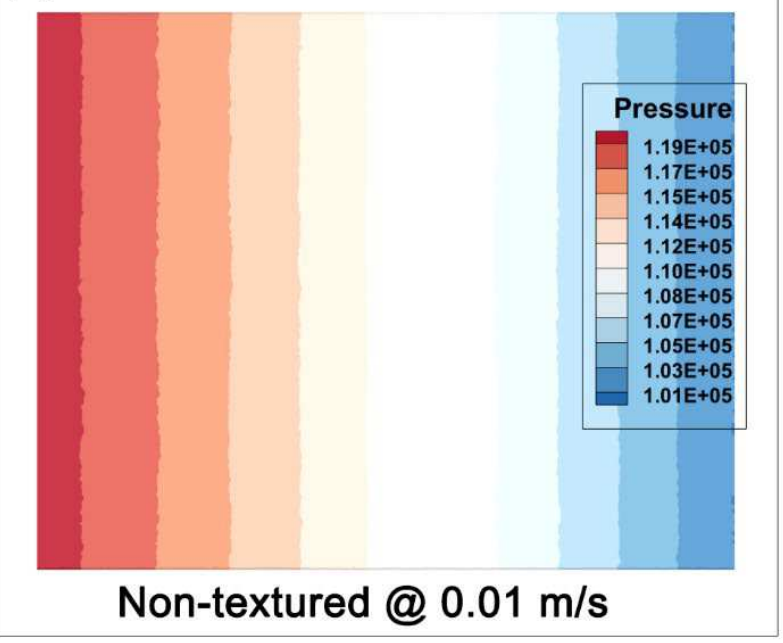

(c)

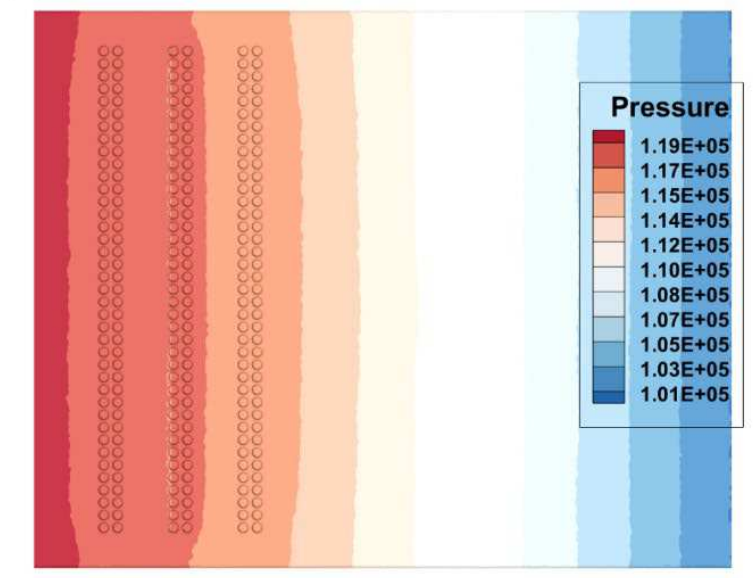

TX-300@ $0.01 \mathrm{~m} / \mathrm{s}$ (b)

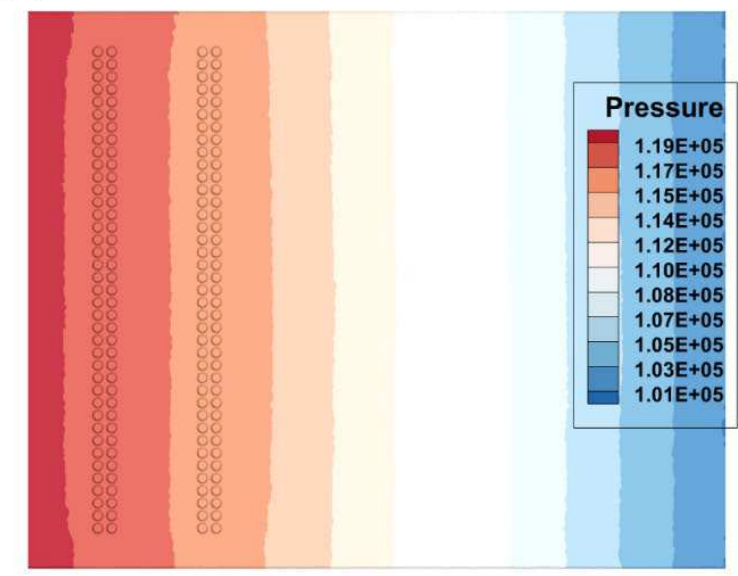

TX-500@ $0.01 \mathrm{~m} / \mathrm{s}$

(d)

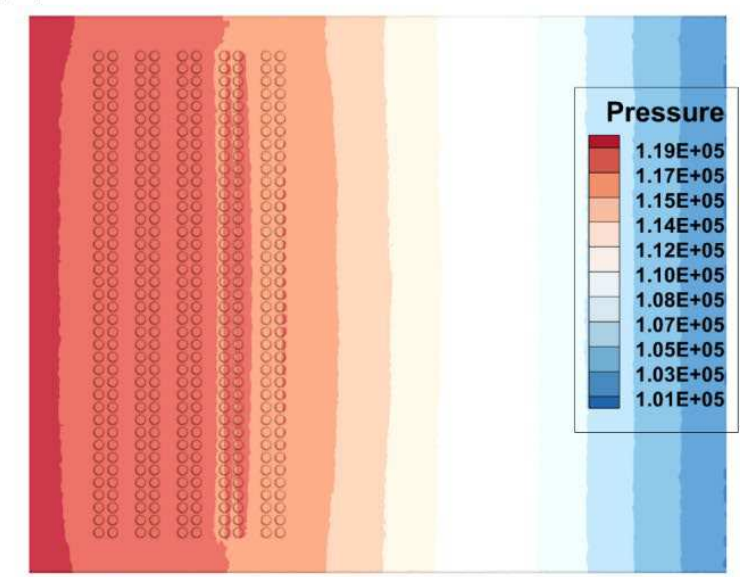

TX-100 @ $0.01 \mathrm{~m} / \mathrm{s}$

Fig. 9. Comparison of pressure distribution on the top surface of the model for Non-textured (a), TX500 (b), TX-300 (c) and TX-100 (d) at top surface .

Simulations with different texture cases are performed at top surface moving speed $0.01 \mathrm{~m} / \mathrm{s}$, and the results in terms of the pressure distribution on the top surface regarding different cases are presented in Fig. 9. Compared to the non-textured case, other three textured cases TX-500, TX-300 and TX-100 show larger high pressure area which is indicated by red. The area and intensity for high pressure increase with the rise of the texture units. It is clearly to see the pressure built up generated by the dimpled groove, especially in Fig. 9 (c) and (d). However, $0.01 \mathrm{~m} / \mathrm{s}$ is the speed applied in the experiment, which is slower compared to the normal operation speed for rotating machine component. Then. The Fig. 10 shows the pressure distribution on the top surface regarding different cases when the top surface moving speed is $0.1 \mathrm{~m} / \mathrm{s}$, 
higher pressure build up are obvious compared to Fig. 9. The integration of the top surfaces pressure is increased by $4.3 \%, 6.1 \%$ and $10.0 \%$ for the TX-500, TX-300 and TX-100, respectively. The texture is more effective when the top moving speed is higher. It indicates that, the proposed texture may have better performance when the lubrication regime is in hydrodynamic lubrication.

\section{(a)}

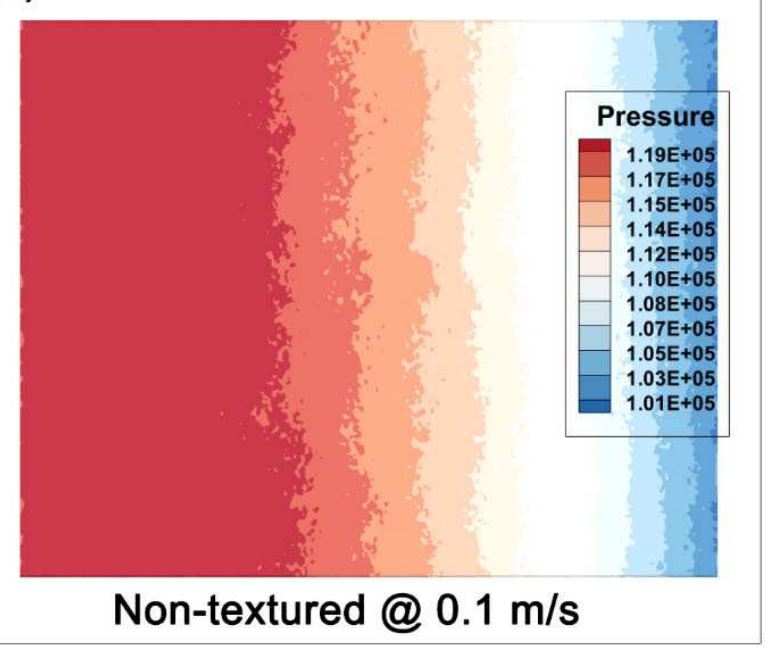

(c)

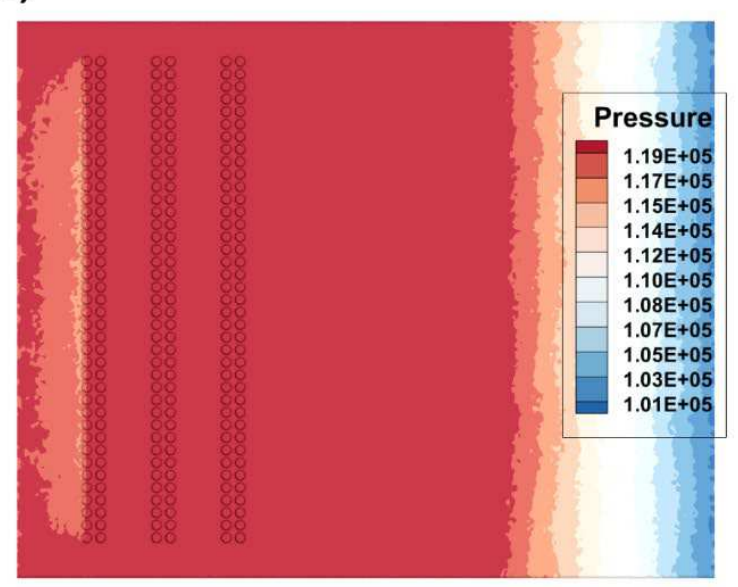

TX-300@ $0.1 \mathrm{~m} / \mathrm{s}$

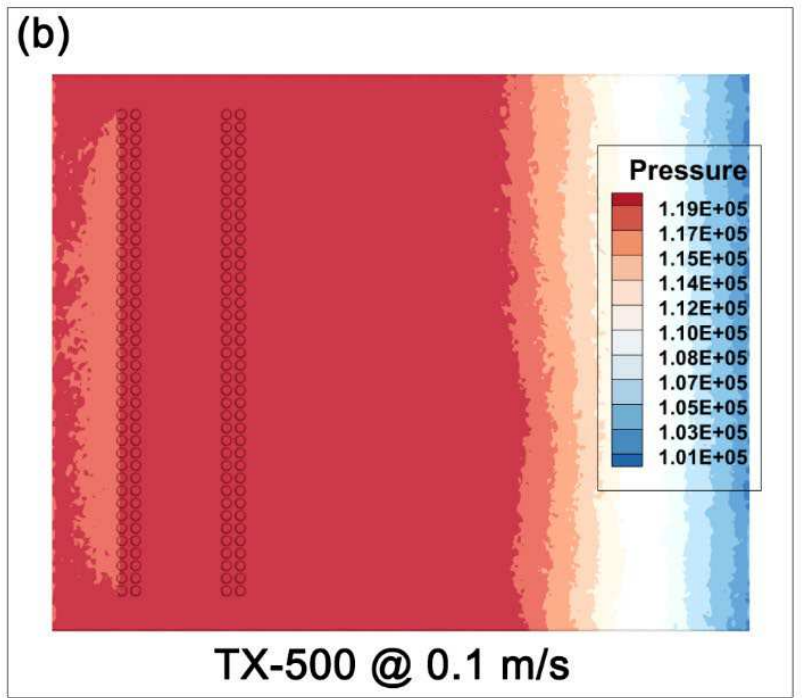

(d)

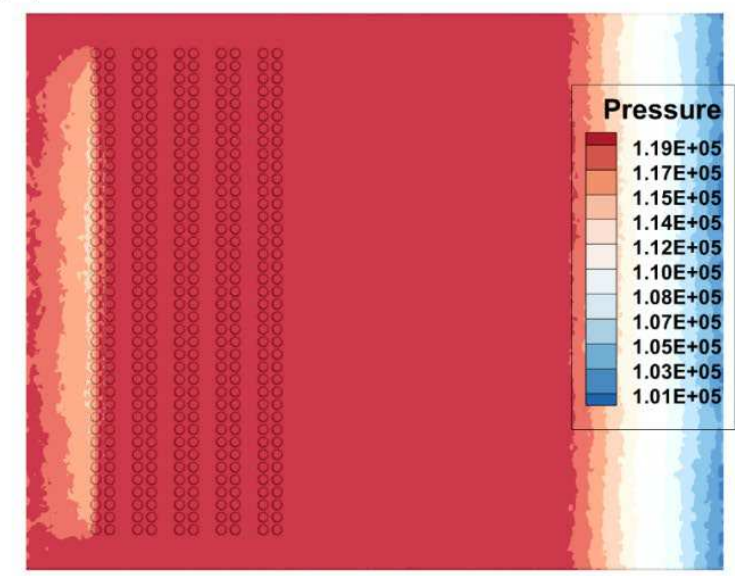

TX-100@0.1 m/s

Fig. 10. Comparison of pressure distribution on the top surface of the model for Non-textured (a), TX500 (b), TX-300 (c) and TX-100 (d) at top surface .

Both simulation and experimental results suggest that, the proposed texture could reduce the friction under a lubricated condition. But the with increase of the texture units, the trends of the friction change for the simulation and experiment are different. It has been reported in many experimental and simulation 
studies that friction is further reduced as texture density increases (Gropper, Wang et al. 2016). In contrast to earlier findings, in this study, as the density of the dimpled grooves increases, the ability of the texture to reduce friction declined. We believe that, there is positive correlation between texture effect and texture density. The opposite finding from experimental results may be caused by the increased contact area brings by the proposed texture unit. As shown in Fig. 5, the laser beam produces dimples and asperities accumulate around each dimple's edge, which leads to a larger contact area. In addition, more disorganized ridges and gullies emerge under complex combined loads at the interface and boundary and in mixed lubrication regimes. It is possible that the disorderly direction of the ridges and the rupture of the partial oil film reduces effect of additional hydrodynamic pressure generation. In other words, the texture may still have drawbacks even if it contributes to successfully reducing friction.

It is worth noting that the proposed texture is produced by a commercial low-power laser marking system that could be purchased at very low cost. In addition, the material that needs to be removed for dimpled groove fabrication is less than that required for the conventional micro-groove texturing process. Further, the commercial laser marking system promises a higher texturing efficiency and consumes less of the proposed texture compared to the conventional micro-groove texturing process. The texturing speed is $1800 \mathrm{~mm}^{2} / \mathrm{min}$ for the TX-500 texture; this speed is fast enough for industrial applications. During the texturing process, there is no waste nor consumption of supplementary materials. In addition, the power consumption of the laser system is low. The texture shape, form, depth, and other features are easily controlled by adjusting the laser source scanner. Thus, the proposed texturing process is a green process compared to other texturing procedures.

In this work, the aforementioned assumptions in the simulation may cause a few limitations. Due to restrictions in terms of equipment, the friction test at higher speeds could not be applied; the texture effect could also not be verified under hydrodynamic lubrication conditions. In addition, the tests are only performed at room temperature. We would like to overcome these limitations as part of future research.

\section{Conclusions}


This study presents a novel preparation scheme of a laser surface texture with micro-dimpled grooves. The procedures of texture design, fabrication, and verification are described in this paper. CFD simulation is performed to provide a reference for comparing texture designs and application scenarios. Reciprocating sliding tests are conducted to examine the performance of the dimpled grooves. The following conclusions are drawn from this study:

- Micro-dimpled grooves can be fabricated using a low cost, pulsed laser system with a short time efficiently.

- A micro-dimpled groove texture with $500 \mu \mathrm{m}$ distance (TX-500) reduces the friction coefficient by $6 \%$ on average in the reciprocating sliding tests.

- As the density of the micro-dimpled grooves increases, friction also increases, which is in contrast to other published studies.

- The CFD simulation suggests that the texture could be more effective under a hydrodynamic lubrication conditions.

\section{Acknowledgement}

We would like to acknowledge Northwestern Polytechnical University in Xi'an China, VINNOVA Sweden's Innovations Agency, and centre for Design and Management of Manufacturing Systems at the KTH Royal Institute of Technology for providing funds to support this research.

\section{Compliance with Ethical Standards}

Conflict of interest On behalf of all authors, the corresponding author states that there is no conflict of interest.

\section{REFERENCES}


Properties and Size Effects of Self-Organized Film." Journal of Tribology 141(5).

Chang, T., Z. Guo and C. Yuan (2019). "Study on influence of Koch snowflake surface texture on tribological performance for marine water-lubricated bearings." Tribology International 129: 29-37.

Chen, Y., J. H. Zhang, B. Xu, Q. Chao and G. Liu (2019). "Multi-objective optimization of micron-scale surface textures for the cylinder/valve plate interface in axial piston pumps." Tribology International 138: 316-329.

Dan, L., Y. Xuefeng, L. Chongyang, C. Jian, W. Shouren and W. Yanjun (2020). "Tribological characteristics of a cemented carbide friction surface with chevron pattern micro-texture based on different texture density." Tribology International 142: 106016.

Gropper, D., L. Wang and T. J. Harvey (2016). "Hydrodynamic lubrication of textured surfaces: A review of modeling techniques and key findings." Tribology International 94: 509-529.

Holmberg, K. and A. Erdemir (2017). "Influence of tribology on global energy consumption, costs and emissions." Friction 5(3): $263-284$.

Kang, Z., Y. Fu, Y. Chen, J. Ji, H. Fu, S. Wang and R. Li (2018). "Experimental Investigation of Concave and Convex Micro-Textures for Improving Anti-Adhesion Property of Cutting Tool in Dry Finish Cutting." International Journal of Precision Engineering and ManufacturingGreen Technology 5(5): 583-591.

Li, C., X. Qiu, Z. Yu, S. Li, P. Li, Q. Niu, R. Kurniawan and T. J. Ko (2020). "Novel Environmentally Friendly Manufacturing Method for Micro-Textured Cutting Tools." International Journal of Precision Engineering and Manufacturing-Green Technology.

Lu, A. G., Y. Gao, T. Jin, X. C. Luo, Q. R. Zeng and Z. T. Shang (2020). "Effects of surface roughness and texture on the bacterial adhesion on the bearing surface of bio-ceramic joint implants: An in vitro study." Ceramics International 46(5): 6550-6559.

Mezzetta, J., J.-P. Choi, J. Milligan, J. Danovitch, N. Chekir, A. Bois-Brochu, Y. F. Zhao and M. Brochu (2018). "Microstructure-Properties Relationships of Ti-6Al-4V Parts Fabricated by Selective Laser Melting." International Journal of Precision Engineering and ManufacturingGreen Technology 5(5): 605-612.

Panigrahi, D. K. and M. Sarangi (2020). "Tribological performance of positive deterministic textured surfaces in parallel sliding lubricated contacts: Effect of texture size and height." Proceedings of the Institution of Mechanical Engineers, Part J: Journal of Engineering Tribology 234(12): 1908-1925.

Rao, X., C. X. Sheng, Z. W. Guo and C. Q. Yuan (2019). "Effects of thread groove width in cylinder liner surface on performances of diesel engine." Wear 426: 1296-1303.

Rosenkranz, A., H. L. Costa, F. Profito, C. Gachot, S. Medina and D. Dini (2019). "Influence of surface texturing on hydrodynamic friction in plane converging bearings - An experimental and numerical approach." Tribology International 134: 190-204.

Schäfer, C., L. Reinert, T. MacLucas, P. Grützmacher, R. Merz, F. Mücklich and S. Suarez (2018). "Influence of Surface Design on the Solid Lubricity of Carbon Nanotubes-Coated Steel Surfaces." Tribology Letters 66(3).

Su, B., W. Huang and X. Wang (2019). "Geometrical Shape Effects of Surface Texture on the Elastic Deformation in Soft-EHL Contacts." Tribology Transactions 62(4): 592-602.

Suh, M. S., Y. H. Chae, S. S. Kim, T. Hinoki and A. Kohyama (2010). "Effect of geometrical parameters in micro-grooved crosshatch pattern under lubricated sliding friction." Tribology International 43(8): 1508-1517.

Tomar, A. K. and S. C. Sharma (2020). "An investigation into surface texture effect on hole-entry hybrid spherical journal bearing performance." Tribology International 151: 106417.

Venkateswara babu, P., I. Syed and S. BenBeera (2020). "Experimental investigation on effects of positive texturing on friction and wear reduction of piston ring/cylinder liner system." Materials Today: Proceedings 24: 1112-1121.

Walker, J. C., S. Cinti, T. J. Kamps, J. Mitchell-Smith and A. T. Clare (2019). "Influence of contact area on the sliding friction and wear behaviour of an electrochemical jet textured Al-Si alloy." Wear 426: 1336-1344.

Wang, L. L., S. H. Guo, Y. L. Wei, G. T. Yuan and H. Geng (2019). "Optimization research on the lubrication characteristics for friction pairs surface of journal bearings with micro texture." Meccanica 54(8): 1135-1148.

Wei, Y., M. R. Kim, D. W. Lee, C. Park and S. S. Park (2017). "Effects of Micro Textured Sapphire Tool Regarding Cutting Forces in Turning Operations." International Journal of Precision Engineering and Manufacturing-Green Technology 4(2): 141-147.

Wei, Y., R. Tomkowski and A. Archenti (2020). "Numerical Study of the Influence of Geometric Features of Dimple Texture on Hydrodynamic Pressure Generation." Metals 10(3): 361.

Yagi, K., W. Matsunaka and J. Sugimura (2021). "Impact of textured surfaces in starved hydrodynamic lubrication." Tribology International 154: 106756.

Zhang, J. H., Y. Chen, B. Xu, Q. Chao, Y. Zhu and X. C. Huang (2018). "Effect of surface texture on wear reduction of the tilting cylinder and the valve plate for a high-speed electro-hydrostatic actuator pump." Wear 414: 68-78.

Zhang, K., X. Guo, C. Wang, X. Meng, L. Sun and Y. Xing (2020). "Effect of Scale and Sequence of Surface Textures on the Anti-adhesive Wear Performance of PVD Coated Tool in Dry Machining SLM-Produced Stainless Steel." International Journal of Precision Engineering and Manufacturing-Green Technology.

Zhong, Y., L. Zheng, Y. Gao and Z. Liu (2019). "Numerical simulation and experimental investigation of tribological performance on bionic hexagonal textured surface." Tribology International 129: 151-161. 
Figures

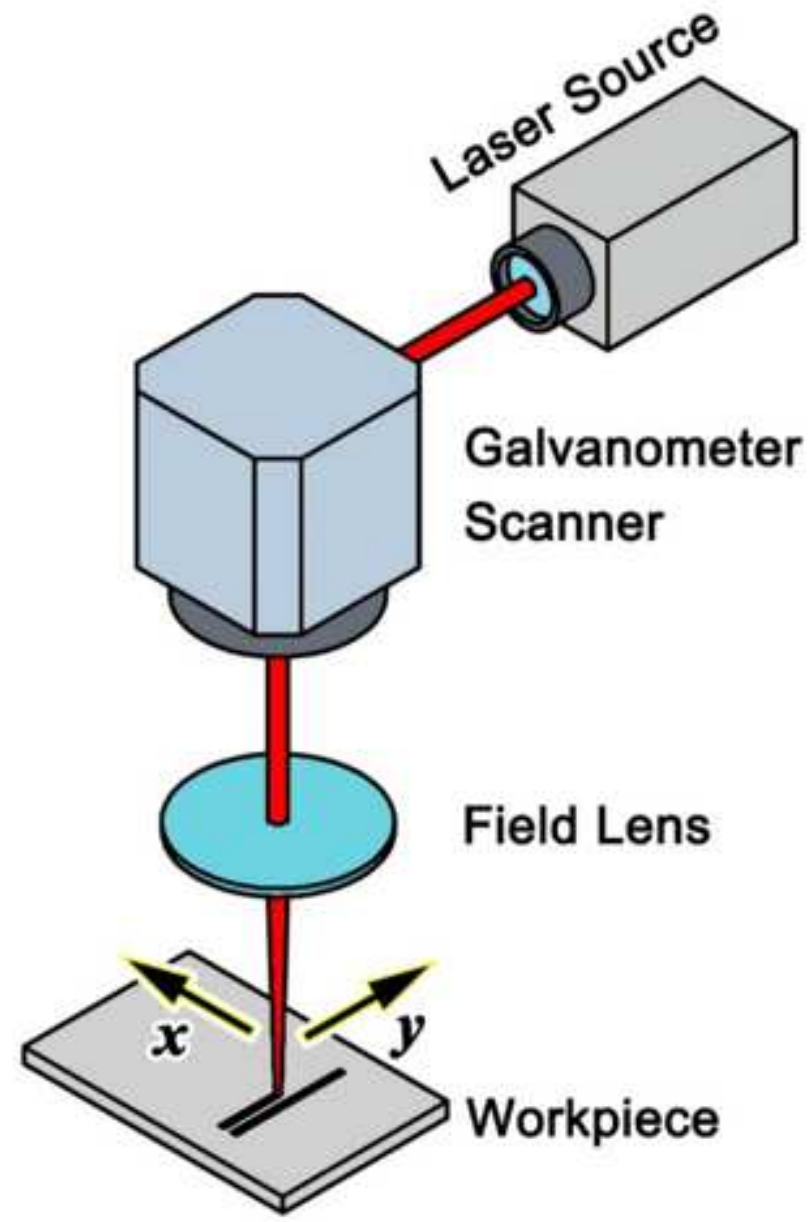

Figure 1

Schematic diagram of the laser marking system 


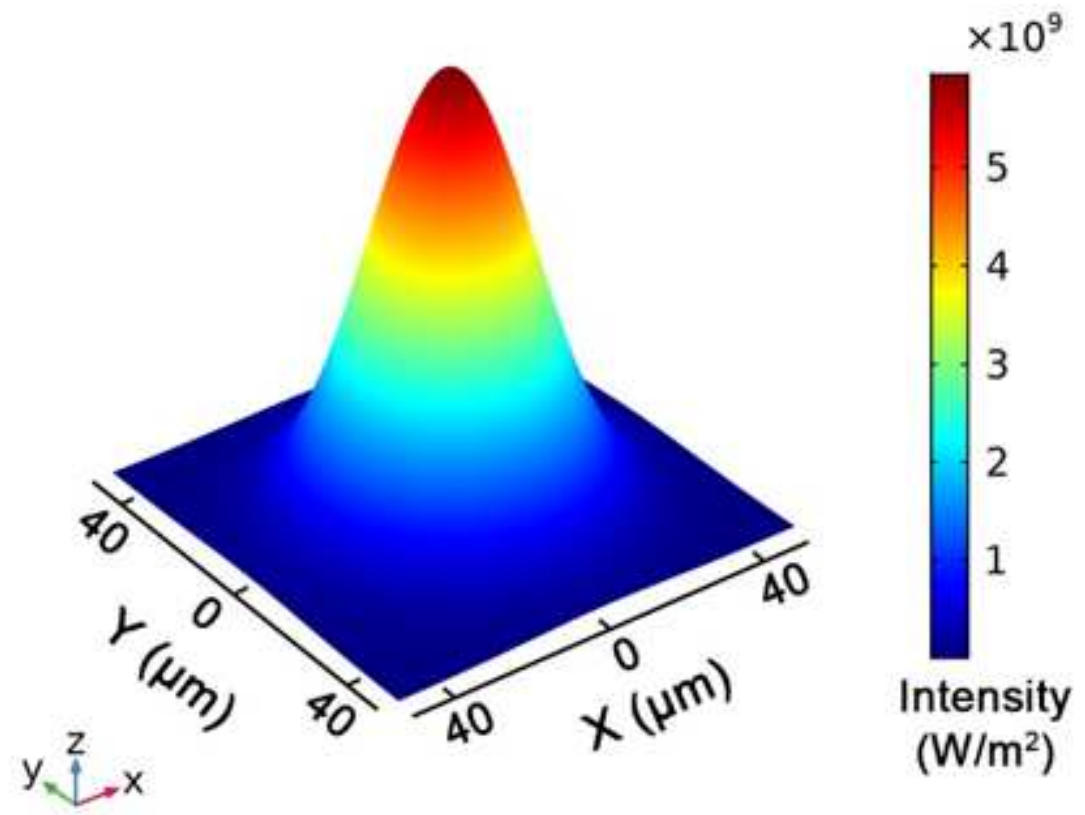

Figure 2

The distribution (Gaussian) of laser beam profile.

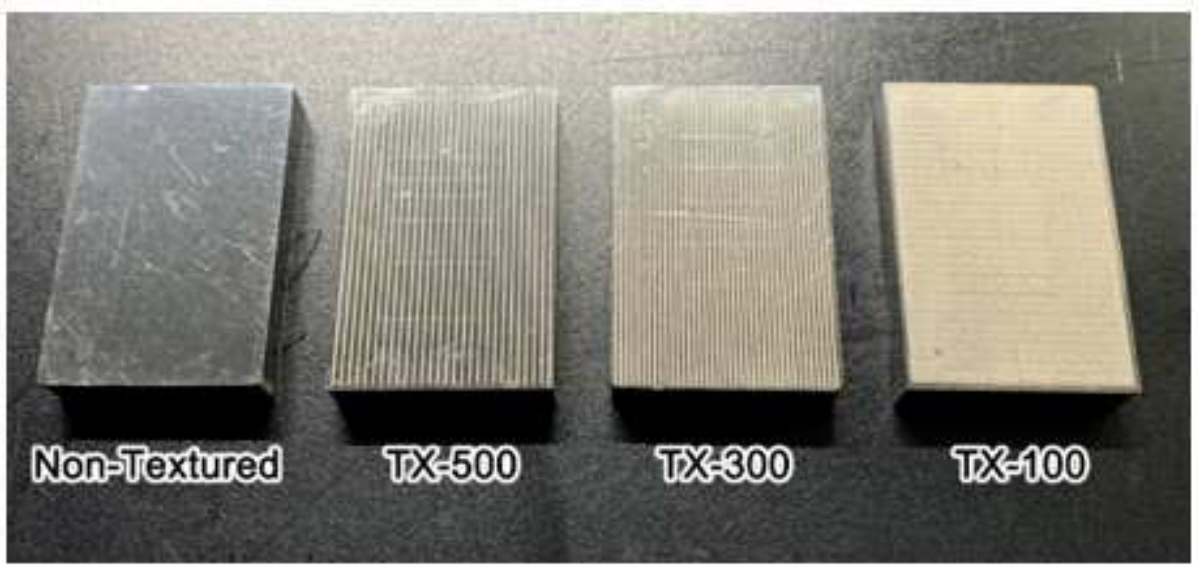

Figure 3

The picture of the workpiece Non-textured, TX-500, TX-300 and TX-100. 

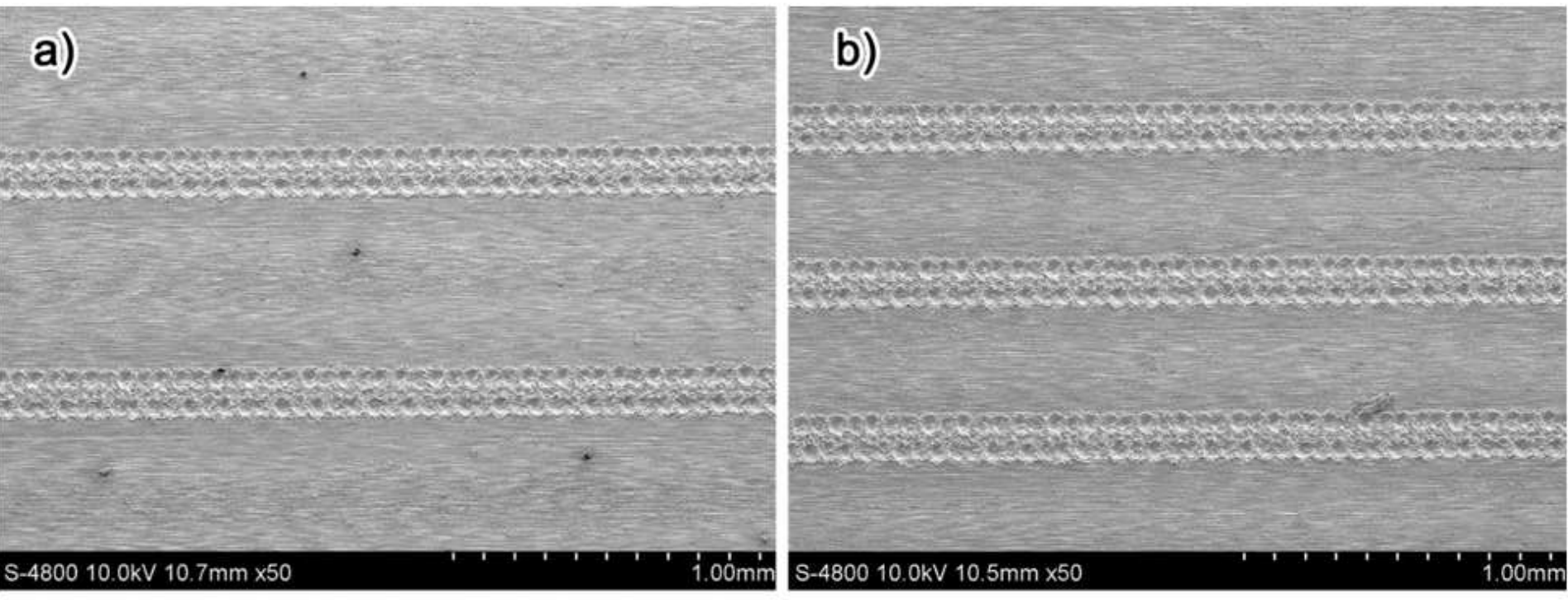

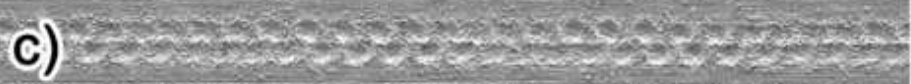

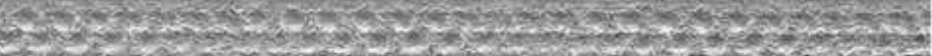

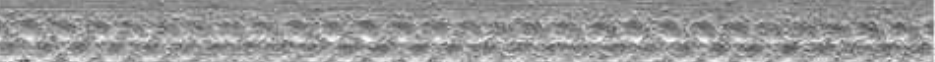
R.

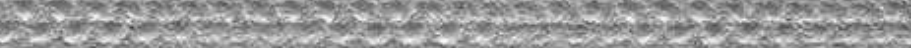

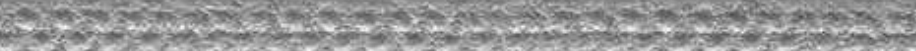

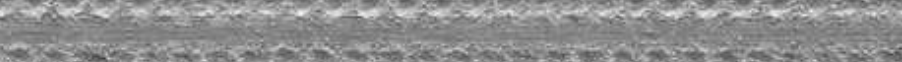

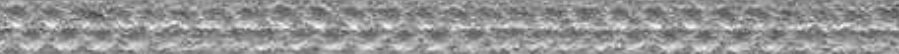

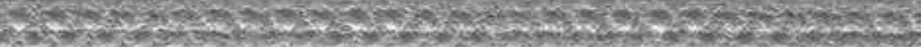

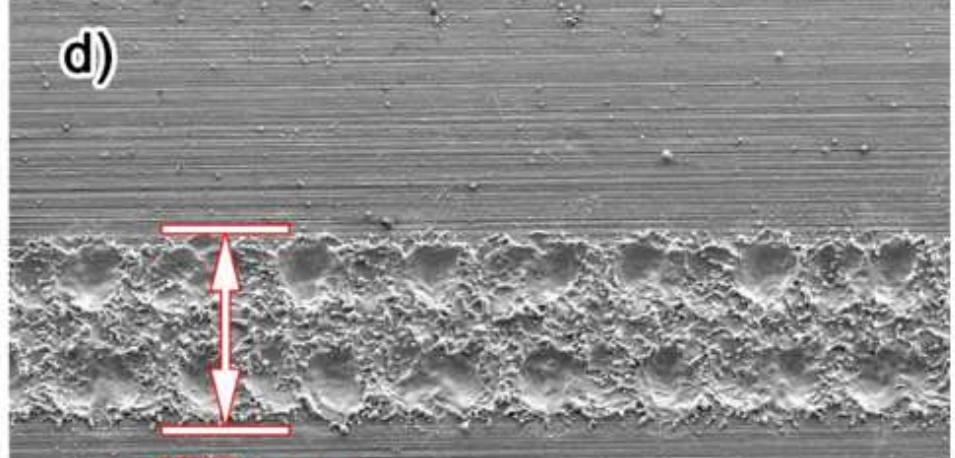

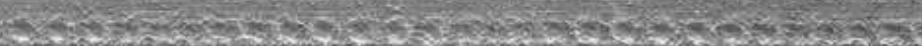

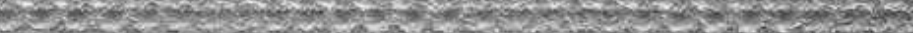

\section{Figure 4}

SEM images of textured surfaces for a) TX-500, b) TX-300, c) TX-100 and d) a partially enlarged groove. 
a)

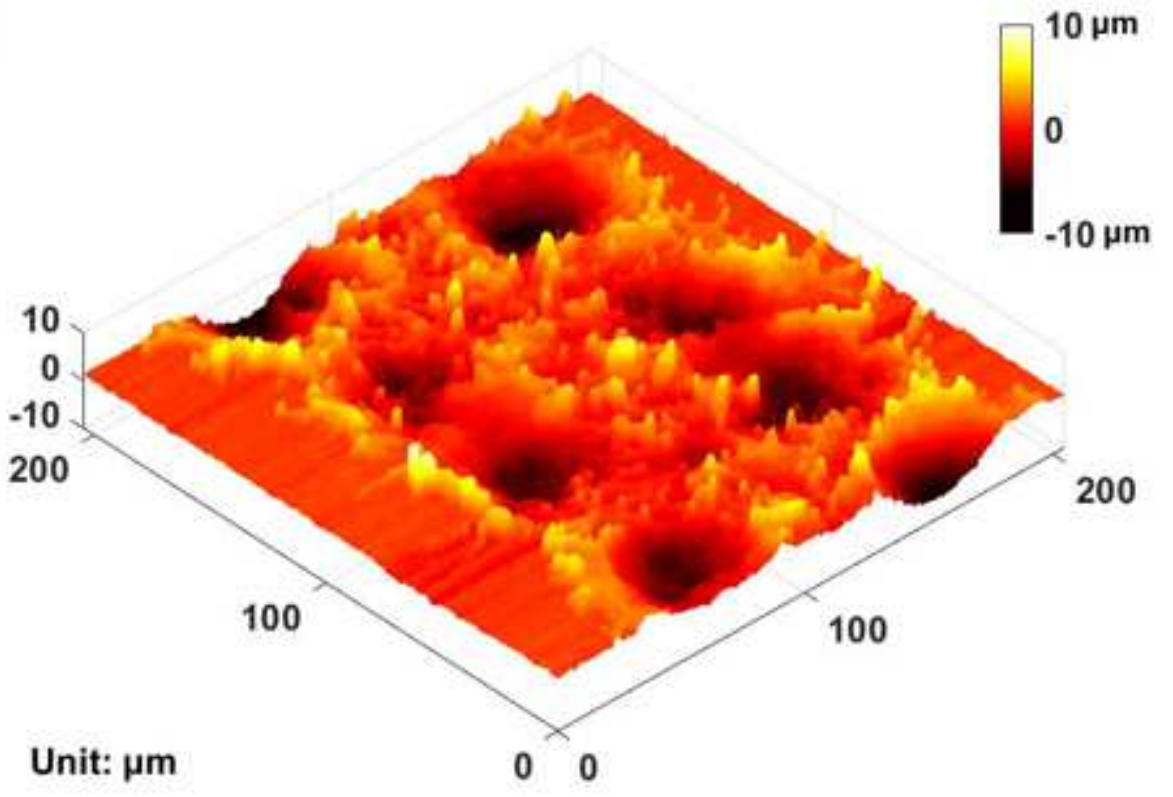

b)

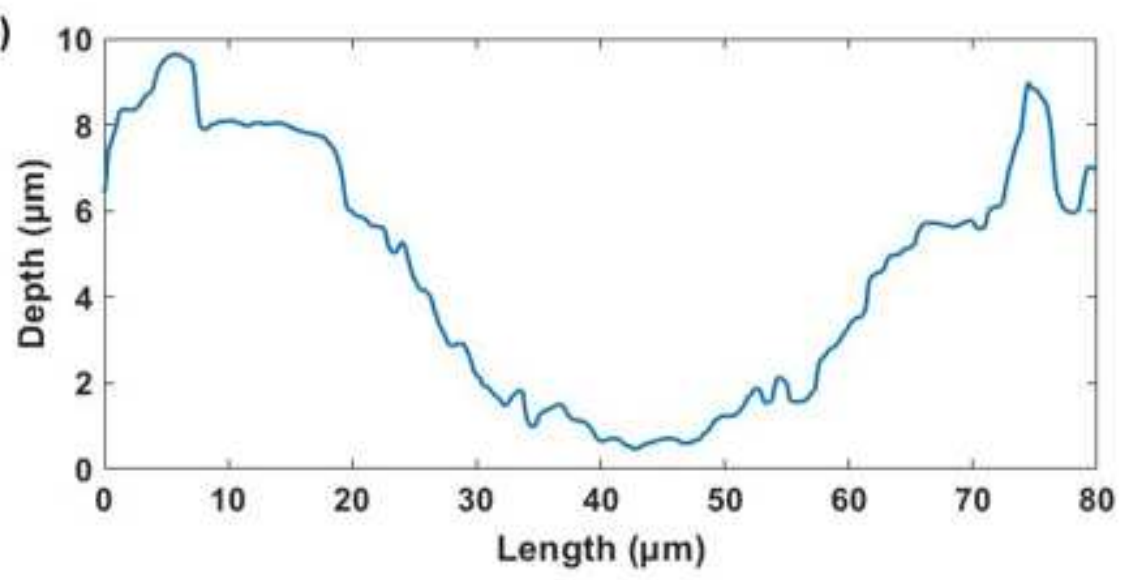

Figure 5

a) Surface profile of the texture and b) profile of a single dimple section (obtained using a NanoMap1000 white light interferometer). 


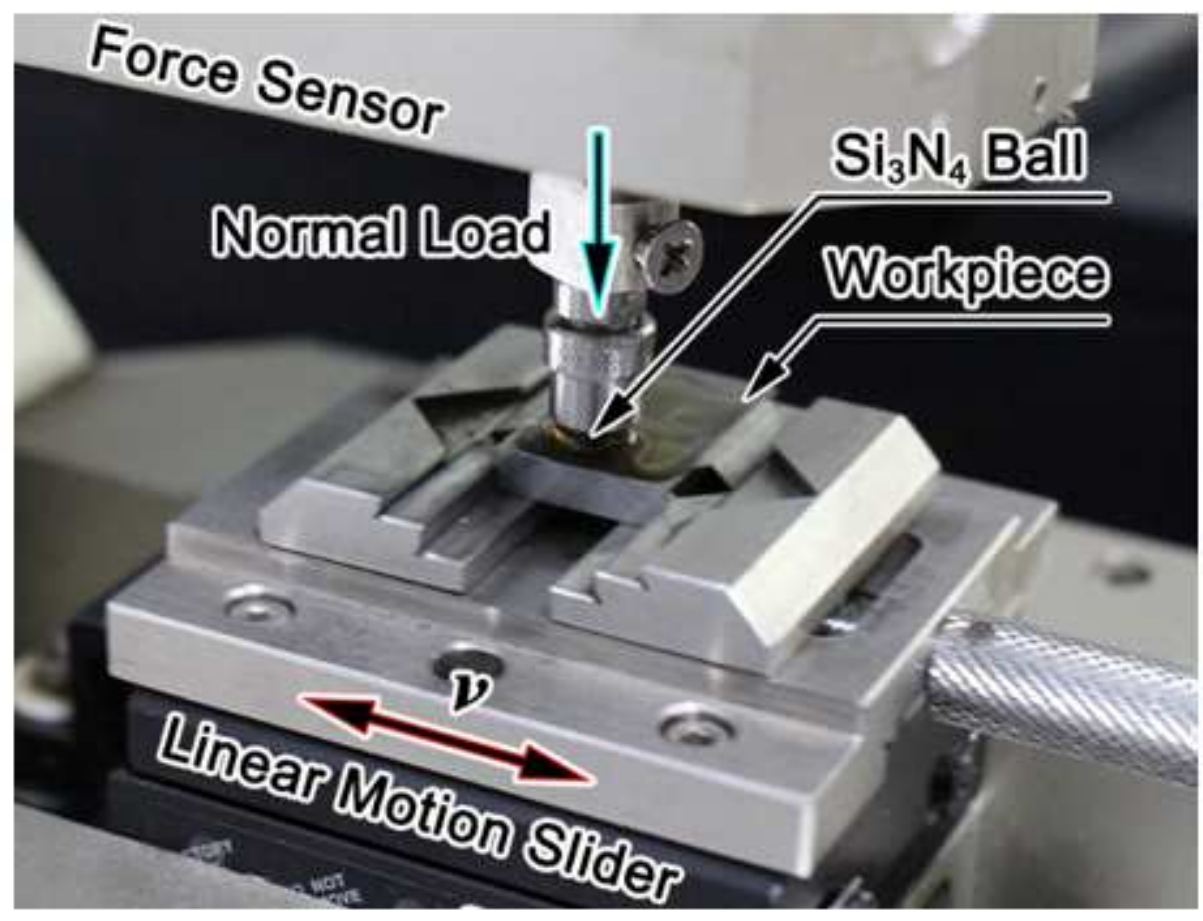

Figure 6

Schematic diagram of the friction tester.

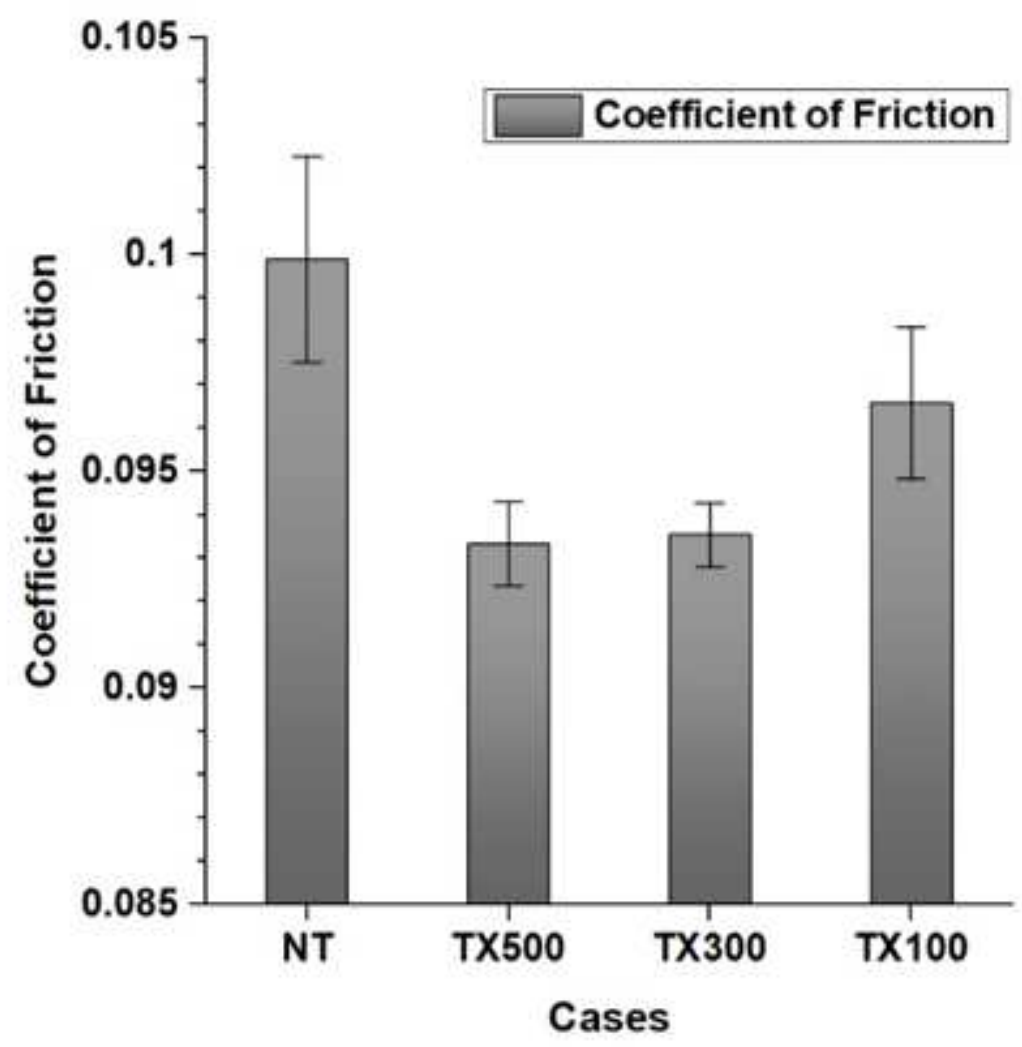

Figure 7 


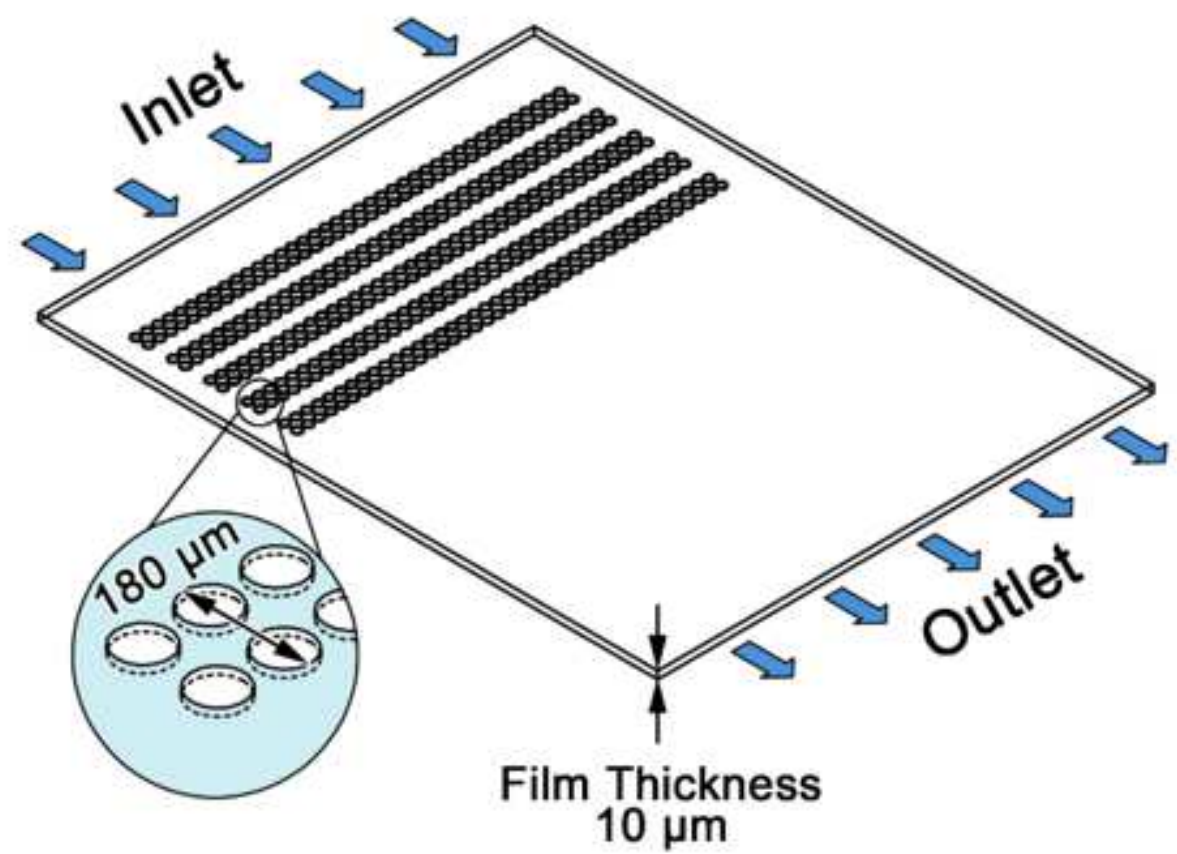

Figure 8

Schematic of the computational fluid dynamics (CFD) model of TX-100 case. 
(a)

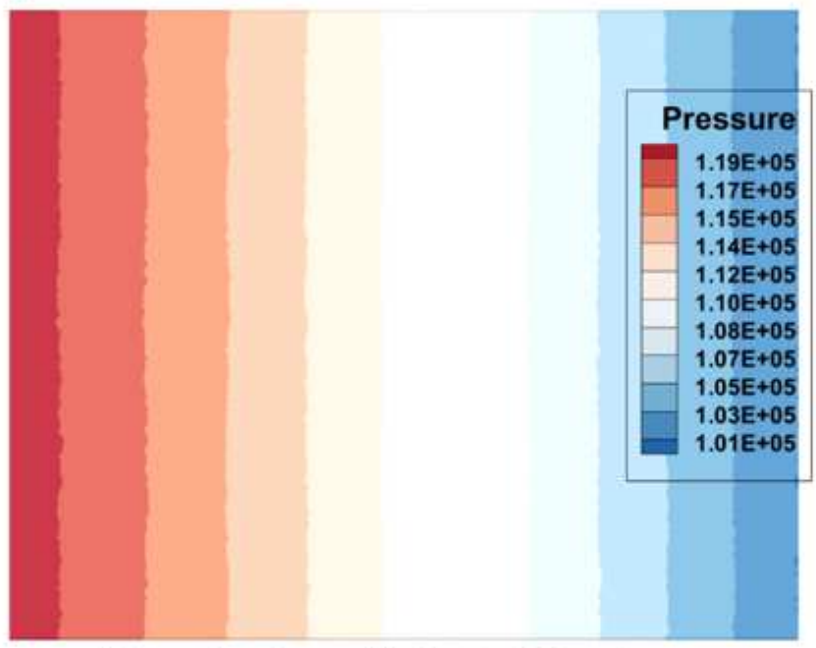

Non-textured @ 0.01 m/s

(c)

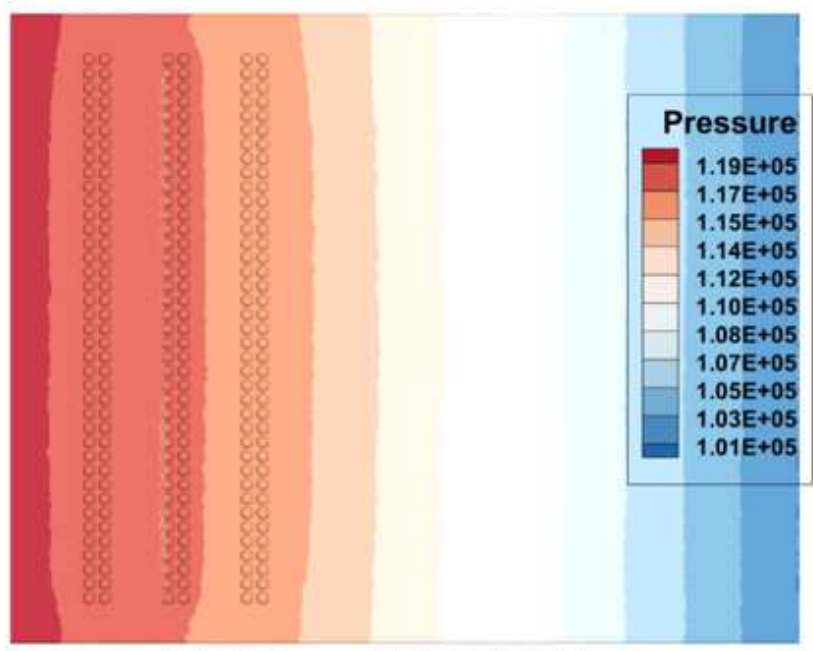

TX-300@ $0.01 \mathrm{~m} / \mathrm{s}$ (b)

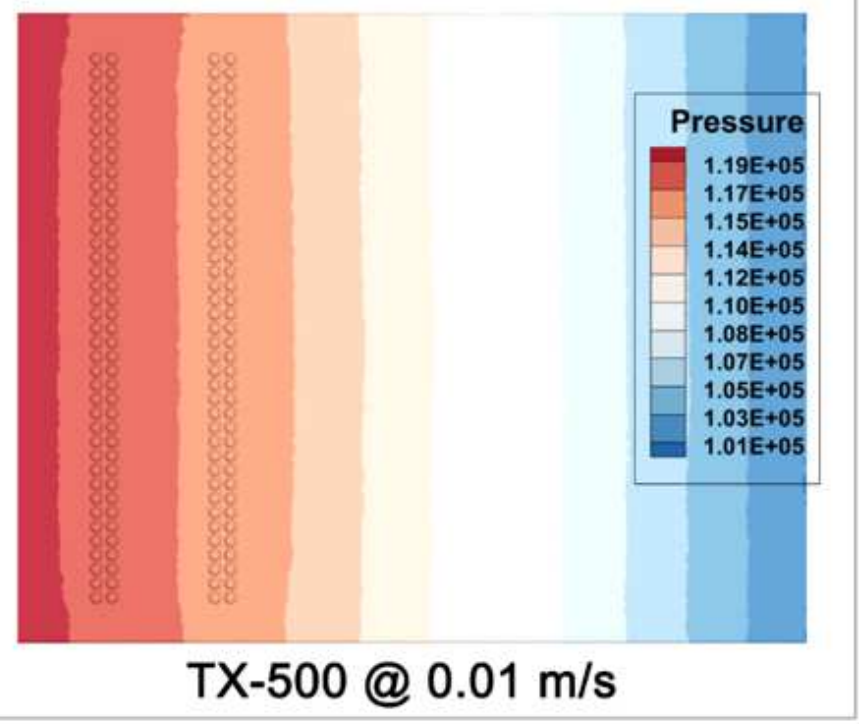

(d)

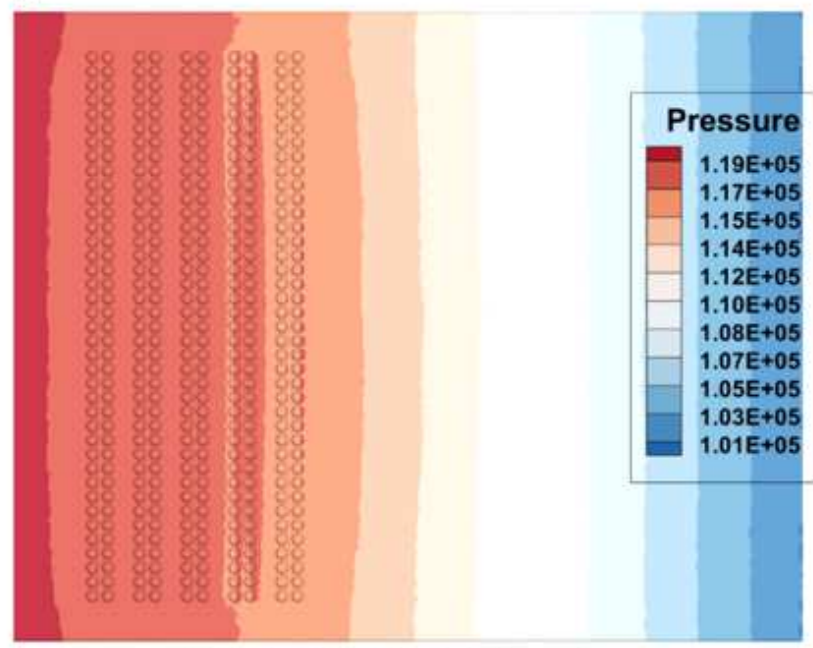

TX-100@ $0.01 \mathrm{~m} / \mathrm{s}$

Figure 9

Comparison of pressure distribution on the top surface of the model for Non-textured (a), TX-500 (b), TX300 (c) and TX-100 (d) at top surface. 
(a)

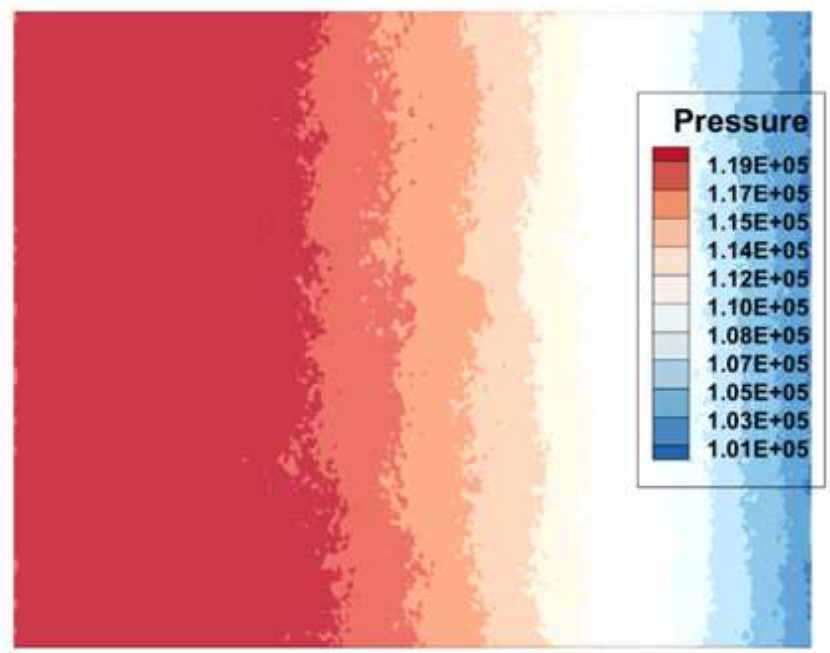

Non-textured @ $0.1 \mathrm{~m} / \mathrm{s}$

(c)

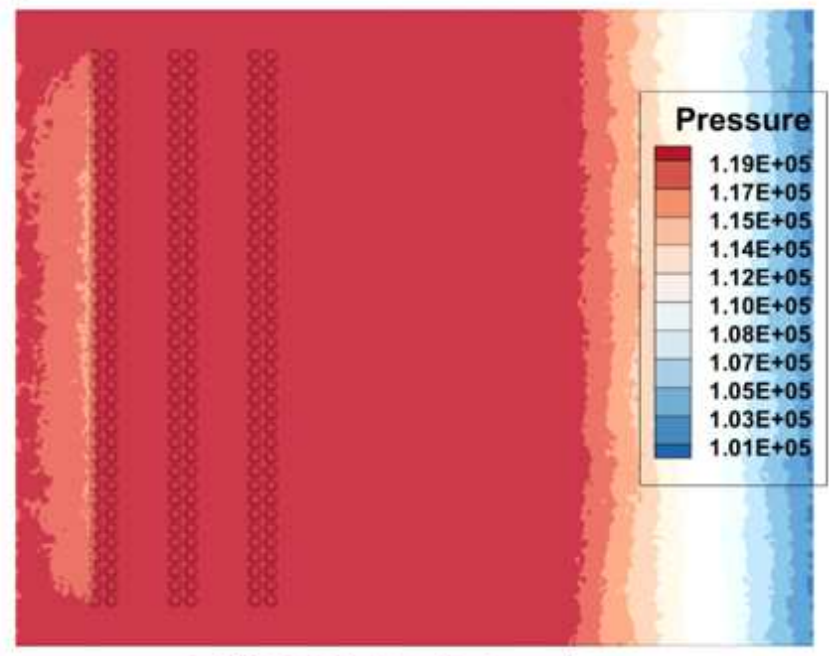

TX-300 @ $0.1 \mathrm{~m} / \mathrm{s}$ (b)

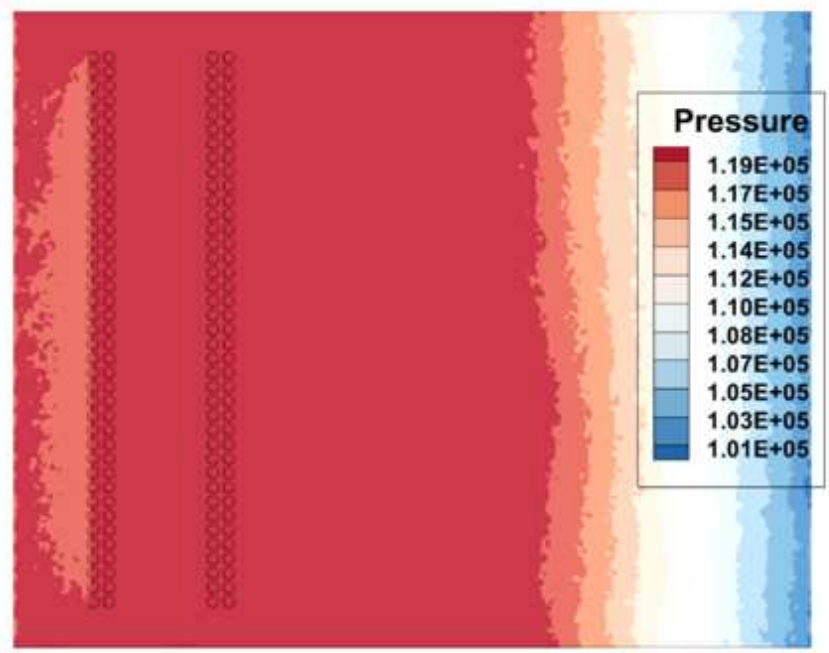

TX-500 @ $0.1 \mathrm{~m} / \mathrm{s}$

(d)

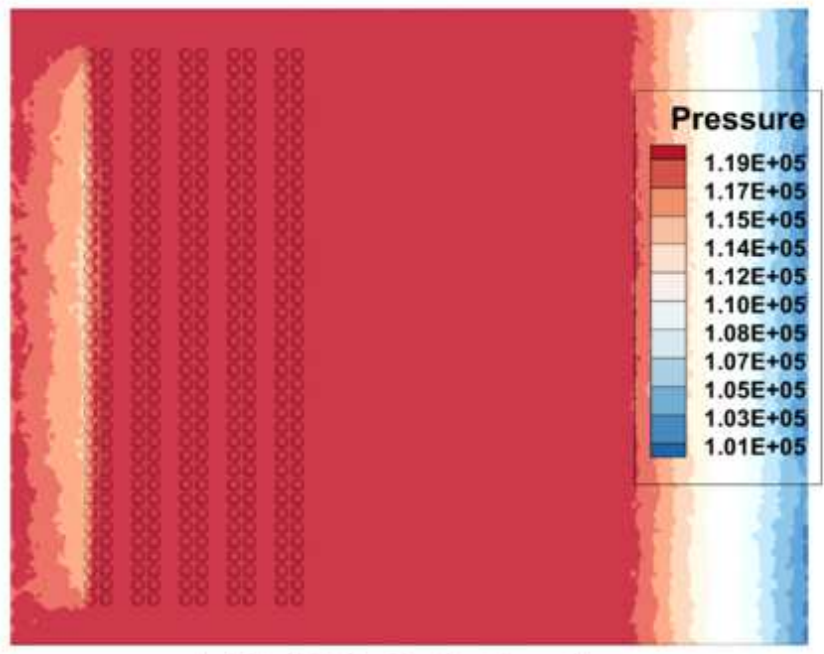

TX-100@ $0.1 \mathrm{~m} / \mathrm{s}$

Figure 10

Comparison of pressure distribution on the top surface of the model for Non-textured (a), TX-500 (b), TX300 (c) and TX-100 (d) at top surface. 